\title{
A.E. Kulakovsky on the issues of the Yakut writing: the analysis of the epistolary heritage of classic master
}

\author{
Praskovia Sivtceva-Maksimova* \\ North-Eastern Federal University named after M.K. Ammosov, 677000, 58 Belinsky str., Yakutsk (Republic of Sakha), \\ Russian Federation
}

\begin{abstract}
The paper presents the letters of Alexey Kulakovsky, who deeply understood the meaning of the language for the future Yakut people. The source study materials are five letters to contemporaries. The relevance of the study is explained by the growing interest in the history of national languages as the basis of the culture of peoples. The purpose of the study is to determine the importance of the main directions in Kulakovsky's creative searches for the preservation of his native language, which reveals controversial issues in the history of the study of Yakut literature in general. The letters reflect such questions as doubts among his contemporaries about the need to defend the rules of Yakut grammar, disbelief in the possibility of the establishment of literary norms in their native language. As a result of the study of the presented material, the author concluded that the issues of language in letters reveal a number of little-known facts on the scientific biography of Kulakovsky because the issues of updating his texts expand the interdisciplinary contexts of their analysis, taking into account the reflection in them of historical and social facts in the early twentieth century.
\end{abstract}

\section{Introduction}

The role, importance of creativity and scientific works of A.E. Kulakovsky in the establishment of the norms of the Yakut literary language is emphasized in many works of Yakut scientists. This study presents the works of Alexei Kulakovsky, who tried to perpetuate the originality of the language of his native people.

The relevance of the topic is justified by the growing interest in the study of the history of literature and the significance of works devoted to the problems of collecting and systematizing materials on language and folklore. The subject of source analysis is five letters by Kulakovsky to his contemporaries, which had not previously become a subject of special study, as well as publications of his works, reviews, reviews of them and articles of different years. As a result of the study of the facts of his life and work, the author revealed the discussions on the study of Yakut literature in general.

Alexey Kulakovsky (1877-1926) was born to a middle-income peasant family. After successful graduation from a modern school in 1897 , he worked as a clerk, then as a teacher in different uluses of Yakutia. He was engaged in collecting folklore, studying the language, beliefs, culture of his native people, riding horses, deer, dog sleds, walking the vast territory of Sakha Land. The multifaceted intellectual heritage of Alexey Kulakovsky is associated with the origins of the formation of a unique Yakut literature, the foundations of the humanities, natural science, sociology, where the main idea reveals the meaning of language in the fate of the people [1].

The purpose of the research is to determine the importance of the main directions in the creative works of Kulakovsky, which is more convincingly confirmed in his epistolary heritage. It also necessary to present the significance of his works on the Yakut language at the beginning of the twentieth century in new context.

The novelty of this analysis is in the confirmation of the research statement of the mutual logical attachment of his appeals to contemporaries with the search for effective ways to establish the norms of the literary language. Due to the growing interest in the history of national languages as the basis of the culture of peoples, the source study of Kulakovsky's letters reveals the issues related to an in-depth study of his work.

\section{Materials and Methods}

The research was performed in the parameters of source study and hermeneutic methods of philology in the context of textual analysis of sources and documents. The methodological basis of the research is presented by the works of P.A. Sleptsova, N.S. Grigorieva, L.R. Kulakovskaya [2; 3; 4], where the significance of Kulakovsky's works on the Yakut language is substantiated and folkloristic methods by P.G. Bogatyrev in the study of living tradition and components of factors, taking into account the deep

\footnotetext{
Corresponding author: smpv50@mail.ru
} 
penetration into the structure of the text and its situational connections $[5,145]$ as part of folk culture.

In this regard, Kulakovsky's epistolary heritage contains facts confirming his ability to highlight topical issues of the time in the assessment of the research of his contemporaries. Kulakovsky's letters reveal real confirmation of the discussions on the establishment of the norms of the literary language of the peoples of Russia at the beginning of the twentieth century.

\section{Results and Discussion}

In a letter dated November 18, 1912, Kulakovsky addressed E.K. Pekarsky (1858-1934), a compiler of the three-volume Dictionary of the Yakut Language. He noted stylistic devices of the Yakut speech not translated into other languages and introduced into the manuscript of the Dictionary. At the same time, he argued his conclusion as follows: "Forgive me if I express my opinion on one particular aspect in your work. I would advise you to delete these words from the Dictionary. You can do this with a clear conscience, ... because each speaker invents a new word during the speech and it is impossible to include into the dictionary even a hundredth part of these words" $[6,181]$

This warning by Kulakovsky revealed one of the main meanings of his heritage, namely, that he studied his native language in the living dynamics of folk speech. In this regard, in the works of Kulakovsky on the Yakut language, a certain historical stage in the formation of the written language of the Sakha people is recorded. The uniqueness of his language is that his epic literature has developed orally since ancient times.

Further in the letter, Kulakovsky revealed the peculiarity of these stylistic devices using an example with a brief presentation of episodes from his own experience in the translation of their meaning. In conclusion, he wrote: "a speaker can say a word that none of the Yakuts had heard before, but, nevertheless, it is able to cause an explosion of laughter in the audience, therefore, it is well understood by the Yakuts". In the postscript, Kulakovsky offerred his help: "My second request is of this kind: will you welcome me to work on the publication of the Dictionary under your leadership" $[6,183]$. The proposal to take part in the work on the Dictionary, which was not approved by Pekarsky, also hada subtext in the form of a hint on how to improve the composition of the Dictionary with the help of a native speaker. It seems that Pekarsky understood this well. Perhaps, he would not be quite comfortable managing such a connoisseur and researcher of the language as A.E. Kulakovsky.

At the stage of the completion of the manuscript of the third volume of the "Dictionary of the Yakut language" [7] in 1924-1928 G.V. Baishev (1898unknown), a Yakut poet, linguist by education worked with Pekarsky. At that time, he studied at the
Leningrad Institute of Living Oriental Languages and worked as the scientific secretary of the Yakut Written Language Committee. After returning to his homeland, he was arrested on charges of nationalism and sentenced for three years in a forced labor camp. The date of his death is unknown. G.V. Baishev was rehabilitated in 1991 by the Presidium of the Supreme Court of the Yakutsk-Sakha SSR due to the absence of a crime event.

After the columns of the third volume of Pekarsky's Dictionary, the information about the authors is given in the section Sources and manuals for the Dictionary of the Yakut language, where there is the information about the cooperation of G.V. Baishev from August 15, 1925 to February 2928. He participated in the processing of materials, made a professional translation into Russian of the olonkho Ala Bulkun. In total, according to the dictionary, we find more than 200 references to the works of Altan Saryn. Moreover, in the Sources the works of A.E. Kulakovsky with the following references: Materials for studying the beliefs of the Yakuts; Yakut proverbs and sayings; Types of animal and plant kingdoms known to the Yakuts. In total, according to the dictionary, we found about 200 references to the works of Kulakovsky [7].

Thus, the historical work of Pekarsky, compiled by him during his exile, made him a famous linguist and ethnographer. Later in St. Petersburg he became a corresponding member (1921), an honorary member (1931) of the Academy of Sciences of the Soviet Union. He lived in Yakutia for over 20 years, much longer than he was in exile. Many native speakers helped him in his work on the dictionary.

In the letters of I.S. Govorov (1856-1925) of the $19^{\text {th }}$ of January and the $9^{\text {th }}$ of February, 1913 we revealed one of the significant aspects of the debate on the problems of the Yakut writing. Kulakovsky turned to "one of the most literate people of his time, Govorov," who was fluent in the Yakut and Russian languages, and was well versed in legal matters. By appointment of the governor I.I. Kraft worked as the head of the organizational department of the Regional Administration, "he had to write many petitions, claims and other documents that required a detailed study of codes of laws and legal documents" [8, p. 6061].

According to the style of Kulakovsky's letters, they were close acquaintances and understood each other well. In the first letter, Kulakovsky asked him for help: "I ask you, uncle, as a yakutologist and patriot, to help me with the following great service for me: either write me a dictionary of the Turkic group of the Ural-Altai languages, or lend your own dictionary. ... Then, can you get me ... the grammar of the Altai language?" [6, p. 185].

In this usual address of the poet to an older friend we revealed that he worked in difficult conditions, how he sincerely strove to perpetuate his native language, possessing a deep knowledge of folk culture. In the second letter to Govorov, he expressed his bewilderment: "I am very surprised, and even 
more upset by that inert attitude of yours, which you showed regarding the Yakut language."

Kulakovsky further wrote that he understood the reasons for his irritated state, he mentioned one of them as follows: "You were expelled at the congress from" ours "because, probably, you always like to express your thoughts openly, without flattery ... as others "politicians" do. We must please and flatter everyone ... We can not trust this letter, written under the influence of momentary discontent that is we can not believe the sincerity of your thoughts about the language" $[6,186]$.

In these extracts from Kulakovsky's letter, a picture of historical significance is presented: by the dating of the autograph, we can unambiguously determine the meaning of the personality of the poet and thinker Alexey Kulakovsky, who was the first to convincingly determine that the future of the native people without the protection of its language can not be reliable. In the early $1910 \mathrm{~s}$, we can assume that, despite his loneliness in this matter, he spoke in favor of the meaning of language for every nation with substantiated evidence.

Further a meaningful and interesting characteristic of the available experiments in compiling the Yakut grammar by O. Bötlingk, D. Khitrov, S. Yastremsky was given in this letter and certain particulars on the composition of E. Pekarsky's dictionary were also indicated. Kulakovsky talked about the special sounds of the Yakut language, the functions of punctuation, graphic complexities when "lettering introduces a terrible regression to reading engine skills". He also demonstrated fluency in shorthand, on this basis, he gave his versions of the graphics of diphthongs.

Concerning doubts about the Yakut writing, Kulakovsky gave a conclusion, humorously revealing his principled conviction. However, the deep subtext of this saying can be equated with the cognitive metaphor of the poet, based on the end-actualization of the observed events as a socially significant historical fact: "I confess, dear uncle, that I have such a high opinion of my native language, that if a Russian heard it, then he would have laughed heartily. The Yakuts, who deify the Russian language, also laughed evilly at my opinion" $[6,188]$.

This one big letter from Kulakovsky ended with words expressing respect for the addressee and love for his children, who at that time were students of the Imperial Kazan and St. Petersburg Universities and the Modern School in Yakutsk: "However forgive my chatter, you were probably tired of it. ...Didn't write about children. Take a bow and hello. February 9, 1913. Kulakovsky" [6, 192]. The presented two letters were published in the reprint of "The works on the Yakut language" by the compiler, the granddaughter of the poet, L.R. Kulakovskaya based on the autographs of the classic from her private archive.

In the letters of Kulakovsky in the 1920s another important issue is revealed, which has become the subject of discussions on the problems of the Yakut writing, where Kulakovsky's reasoning bribes with the logic and scientific validity of his conclusions. The main issue of discussion here is the need to choose the Cyrillic graphics. It also reveals the desire to convince a certain part of the intelligentsia of the inconsistency of international transcription based on the Latin alphabet as the official beginning of the new Yakut writing.

In a letter to S.A. Novgorodov (1892-1924) on December 4, 1920 [9] Kulakovsky addressed a scholarly linguist and socio-political figure in Yakutia. Semyon Novgorodov graduated from the Yakut modern school, studied at the St. PetersburgPetrograd University since 1913, graduated from it in 1923. In 1917 he presented the first version of the Yakut alphabet based on the Latin alphabet. From 1923 he worked as a researcher at the Institute of Comparative History and Theory of Literature and the Languages of the West and the East at Petrograd University. Since 1922 he was a member of the Yakut representation of the People's Commissariat for Nationalities. His works "The first steps of the Yakut writing: articles and letters" (1978), "In the name of enlightenment of the native people. Works, correspondence, materials" (1991) published by the famous Yakut linguist E.I. Korkina.

Kulakovsky in his letter raised the issue of the illogical choice of the basis of the Yakut writing system for the international phonetic alphabet without capital letters and punctuation marks. He knew Novgorodov, in this regard, his appeal to him was perceived as a continuation of their oral discussions of this issue: "I hoped that, having worked with the children at school, you would see these shortcomings in practice ... And this is all the more insulting that you are going contrary to its basic principle - to be useful to the Yakuts". Then he gave his proofs. "The following fact is especially offensive: you have become so blind before the authority of some professor who asserts that there may be languages for which punctuation may not be applicable. ... Basically, what are punctuation marks? In my opinion, these are the same letters, but dumb, and they are sometimes more eloquent than ordinary letters" [9, 1. 2.].

Kulakovsky revealed his preference for Cyrillic graphics, which were familiar to the Yakuts. In this regard, Yin did not deny that the individual sounds of two different languages were fundamentally different in pronunciation and proposed to introduce letters that expressed the sounds inherent in Yakut speech. The letter ended with Kulakovsky's good wishes in verse form in the volume of 27 lines, which was framed in 7 stanzas. Date, signature: "December 24, Your A." and a postscript was: "Leave the Dictionary of Pekarsky, Maak, Priklonsky. I will read it in the city and leave it with Nikolay Egorovich" [9, 1. 7].

These words confirmed their friendship. Kulakovsky was kind addressing the young colleague, despite their different beliefs on a serious issue. It also revealed the strength of his desire to search for ways to form the Yakut writing as one of the main foundations for the development of education and culture. 
Kulakovsky's letter from 1920 to the secretary of the Yakutsk regional bureau of the RCP (b) Isidor Barakhov (1898-1938) presented an official appeal to the official in order to familiarize him with the projects of the Yakut graphics based on the Cyrillic and Latin alphabet, which justified the choice of the Russian alphabet, which would be necessary to know and study for everyone as residents of the region within Russia. He argued the Novgorodovs' preference for Latin graphics in the following convincing way: "Why did Novgorodov use Latin letters as the basis of his transcription? Because he was more linguist than the Yakut" [10, L. 17].

In the next letter from Kulakovsky to Barakhov, written three years later, the author found clarifications on the controversial issues on the Yakut writing: "In Yakutsk, they do not want to accept my letters solely for material reasons. In addition, I do not have any authority here, as a non-partisan person, because the political fever in people's blood has not cooled down yet" [11, 1. 23]. Kulakovsky admitted that the case was lost, but reported with great enthusiasm about his joy at the introduction of punctuation marks. He noted that this decision was like a significant victory over Novgorodov's mistake.

The author refers to the authoritative opinion of P.A. Sleptsova on the issue of Latin graphics: "Of course, Novgorodov's personality also played a certain role in the choice of the Latin alphabet, but only because Novgorodov's choice corresponded to the opportunities that were provided by the collective political thinking of the environment" [12, p. 11].

The third letter to I. Barakhov dated February 22, 1925 was interesting because Kulakovsky informed him about his works on various issues of the study of the Yakut language. It defined the artistic characteristics and perspectives of studying the lexical richness of the native language. He also presented his work on the rules of pronunciation of specific sounds, emphasized the importance of folklore and ethnographic materials. He informed about the completed works of the dictionary type on proverbs and sayings, on the lexical features of neologisms, dialects of different uluses and districts of the Yakutsk region.

He also reported on the work "Types of animal and plant kingdoms known to the Yakuts" [13]. These works of Kulakovsky were published in the early 1920s by public organizations of the republic and the Yakut department of the Russian Geographical Society. Subsequently, Kulakovsky's scientific works were published by the Institute of Language, Literature and History of the Siberian Branch of the USSR Academy of Sciences [14].

In our opinion, in this letter to I. Barakhov one of the significant, bold conclusions of Kulakovsky in relation to the problems of the Yakut writing was revealed. It provided a convincing substantiation of the question of the impossibility of scientific systematization of the national language without practical knowledge of it: "Why is the compilation of the Yakut grammar entrusted to a Russian person, even a scientist. After all, one theoretical knowledge of a linguist was not enough for this matter. By the way, I managed to discover the rules about the declensions of the variable parts of the Yakut oral language, which are quite natural. It turned out that our language is remarkably correct in relation to grammatical forms, which is partly proved. I placed all declensions in only two diagrams and wrote explanatory rules for them that neither Khitrov, nor Betlingk, nor Yastremsky could discover. I do not know if Poppa will succeed" [13, 1. 19].

Kulakovsky wrote about the authors of the grammar of the Yakut language. D.V. Khitrov (18181896), Bishop of Yakutsk and Vilyui, lived in Yakutia in 1870-1883. He was a missionary, one of the translators of sacred texts and liturgical literature into the Yakut language. For these editions he developed a "Brief grammar of the Yakut language" and "Primer (1858) [15].

O.N. Betlingk (1815-1904) studied Oriental languages at St. Petersburg University, including Arabic, Persian and Sanskrit. He was a member of the Imperial Academy of Sciences. He developed a transcription of the Yakut language, wrote "Memories" by A.Ya. Uvarovsky, a native speaker who lived in the middle of the 19th century. not far from St. Petersburg. From the words of Uvarovsky, his work "On the language of the Yakuts" (1851) was included, as well as records of the olonkho text, many proverbs and sayings [16].

S.V. Yastremsky (1857-1941) was exiled in 1886 to Yakutia for active revolutionary activity after imprisonment. Since 1996, he served in the Irkutsk branch of a trading bank, took part in the work of the East Siberian department of the Imperial Russian Geographical Society. He wrote the book "Grammar of the Yakut language" (1900) [17]. N.N. Poppe (1897-1991) was a Russian linguist and ethnographer. In 1920-1930 he worked at the Leningrad University, since 1926 he worked as a professor, he was the scientific supervisor of the diploma of S.A. Novgorodov, a compiler of the educational grammar of the Yakut language based on international phonetic transcription $[6,207]$.

Thus, the issues of actualization of the texts of Kulakovsky's letters revealed his personal qualities as a deep connoisseur of the original culture and language of his native people. In this regard, his research, scientifically grounded arguments on the problems of language and writing are the source of national linguistics associated with the issues of the study of the language of the peoples of Russia.

The famous Yakut linguist N.S. Grigoriev in the early 1940s determined the significance of Kulakovsky's works on the Yakut language, highlighting 4 main aspects: a) his observations were recorded "in the historical stage of the life of the people and their language"; b) Kulakovsky, is "an outstanding poet-thinker", therefore his "statements about his native language are of great scientific importance"; c) practical materials of linguistic works were collected by him "on the vast territory of 
Yakutia for many years, which is a true scientific feat" [3, p.53]; d) his works do not lose scientific and practical significance in terminology, lexicology, dialectology, phraseological units and the foundations of the literary norms of the Yakut language.

\section{Conclusion}

As a result of the study of the presented material, namely the letters of Kulakovsky to contemporaries, the history of discussions of the main issues of the Yakut writing is traced, starting from 1913. During this period, Kulakovsky was already closely involved in the establishment of grammatical and literary norms of the Yakut language. In general, if his works on the language date back to 1924-25, then it is possible to assume that these dates, in some cases, refer to the first publications of the works.

The letters reflect such social factors as the doubts of contemporaries in the ability to explain the rules of the Yakut graphics, disbelief in the establishment of the norms of their native language. Kulakovsky contrasted their doubts with the fact that "foreigners introduce a lot of their own, but alien". Thus, he proved that one should treat one's native language with respect, with an understanding of its importance, first of all, to the people in general.

The paper is prepared as a part of RFBR research project № 19-012-00467a "Historiographic Aspects of the Study of the Role of Christian Culture in the Development of Yakut Writing and Literature".

\section{References}

1. P.V. Sivtceva-Maksimova, Etnografía y folclore de los Yakuts en las obras de A. E. Kulakovsky en el contexto de la textología, Revista de Investigación Apuntes Universitarios. 11(1), 46-54 (2021)

2. P.A. Sleptsov, A.E. Kulakovsky and the fate of the native language from Ivanov V.N. (ed.) Kulakovsky and time: collection of scientific articles, 366-407 (Art-Flex, Moscow, 2003)

3. N.S. Grigoriev, The significance of the works of A.E. Kulakovsky on the Yakut language from L.R. Kulakovskaya (ed.) Kulakovsky A.E. Works on the Yakut language, 51-59 (Yakutia, Yakutsk, 2017)

4. L.R. Kulakovskaya, Scientific biography of A.E. Kulakovsky. The personality of the poet and his time (Nauka, Novosibirsk, 2008)

5. P.G. Bogatyrev, Functional and structural study of folklore (little-known and unpublished works) (IMLI RAN, Moscow, 2006)

6. L.R. Kulakovskaya (ed.), Kulakovsky A.E. Works on the Yakut language (Yakutia, Yakutsk, 2017)

7. E.K. Pekarsky, Dictionary of the Yakut language, III (Academy of Sciences of the USSR, Leningrad, 1927)
8. A.A. Moyakunova, From the history of social thought at the turn of the XIX-XX centuries: to the question of the author's pseudonym "Yakut", North-Eastern humanitarian bulletin, 4(33), 58-64 (2020)

9. YSC SB RAS, f. 4, op. 9, d. 129, 1. 1-7ob.

10. FNA RS (Y), f. 181, op. 2, d.38, 11. 17-18ob.

11. FNA RS (Y), f. 181, op. 2, d.40, 1. 23-23ob.

12. P.A. Sleptsov, Historical, cultural and theoretical foundations of S.A. Novgorodova from S. A. Novgorodov and the problems of writing of the peoples of Russia, Materials of the All-Russian scientific conference dedicated to the $125^{\text {th }}$ anniversary of the birth of the first Yakut scientist-linguist S.A. Novgorodova, 811 (2017)

13. FNA RS (Y), file 181, op. 2, d.38, 11. 19-20

14. A.E. Kulakovsky, Scientific works (Yakutsk, 1979)

15. D.V. Khitrov, Brief grammar of the Yakut language (Synodal Printing House, Moscow, 1858)

16. O.N. Betlingk, Uber die Sprache der Jakuten: Grammatik, Text und Worterbuch, (Saint Petersburg, 1849-1851)

17. S.V. Yastremskiy, Grammar of the Yakut language (Steam typographic lithography by P.I. Makushin in Irkutsk, Irkutsk, 1900) 